\title{
Thermal Decomposition Behavior Study of Two Agricultural Solid Wastes for Production of Bio-Fuels by Pyrolysis Technology*
}

\author{
Momtaz PARVEEN**, Mohammad Rofiqul ISLAM*** and Hiroyuki HANIU** \\ **Department of Mechanical Engineering, National University Corporation Kitami Institute of Technology, \\ 165 Koen-cho, Kitami City, Hokkaido 090-8507, Japan \\ ${ }^{* * *}$ Department of Mechanical Engineering, Rajshahi University of Engineering \& Technology, \\ Rajshahi-6204, Bangladesh \\ Mrislam1985@yahoo.com
}

\begin{abstract}
In this study pyrolysis kinetics of jute stick (white jute: Corchorus capsularis; tossa jute: Corchorus olitorius) and tamarind (Tamarindus indica) seed available in Bangladesh have been investigated thermogravimetrically in a nitrogen atmosphere at heating rates of 10 and $60^{\circ} \mathrm{C} / \mathrm{min}$ over a temperature range of 30 to $800^{\circ} \mathrm{C}$. The two biomass solid wastes exhibited similar behaviors in that, the weight loss region is shifted to a higher temperature range and the weight loss rate is increased with increasing heating rate. The percentage of total weight loss is higher for jute stick and is lower for tamarind seed. The overall rate equation for the two biomass wastes has been modeled satisfactorily by one simplified equation from which the kinetic parameters of unreacted materials based on the Arrhenius form can be determined. The predicted rate equation compares fairly well with the measured TG and DTG data.
\end{abstract}

Key words: Jute Stick, Tamarind Seed, Thermal Decomposition Behavior, Bio-Fuels, Pyrolysis Technology

\section{Introduction}

Agricultural biomass can be used as raw material to generate alternative liquid, gaseous and solid fuels. To achieve this, thermal decomposition methods such as pyrolysis and gasification are the most appropriate and therefore, the most commercially used technology (Gracia et al., 2002; Bridgwater et al., 2002). The increasing interest in the thermal conversion of biomass for producing alternative fuels necessitates fundamental understanding of processes involving pyrolysis of biomass. Knowledge of the kinetics of thermal reactions is vital to predicting the behavior of biomass. Thermal decomposition mechanism must be known so that the design and control of these processes can be carried out. Many pyrolysis kinetic behaviors studies for different agricultural solid wastes have been reported in literatures (Min et al., 2007; Caballero et al., 1997; Williams and Besler, 1993). However, there is no study concerning the pyrolysis behaviors of jute-stick and tamarind seed. Bangladesh is one of the world's leading producers of jute. More than $30 \%$ of jute of the world is produced in Bangladesh. About 1 million metric ton jute is produced annually in Bangladesh. Jute-stick is the residue of the jute plant and annual generation of this residue is about 1.5 million metric ton. The traditional usages of jute-stick are as fuel for cooking, raw material for paper and pulp industries and apportion has low graded usage.

The tropical/subtropical based climate of India, Bangladesh, Africa, Australia, Florida, Malaysia, Oceania, Philippines, and Seychelles is suitable for growing tamarind plants. The 
tamarind seed is $40-44 \mathrm{wt} \%$ of the whole tamarind fruit. A single tree can generates $60-200$ $\mathrm{kg}$ seeds each year. Annual production of tamarind seed in Bangladesh is about 12000 metric ton. Some countries use the seed to manufacture tamarind kernel powder while in Bangladesh it is accumulating as solid waste. Jute-stick and tamarind seed transformation into high energy-density renewable fuels, like charcoal and bio-oils, can significantly increase profitability of jute and tamarind plantations. Thus, energy recovery from jute-stick and tamarind seed by pyrolysis technology may be worthwhile. Thermal decomposition is not only a part of the pyrolysis process; it is also a first step in gasification and combustion processes. The rate of heat supply, total energy and operation time are the important design parameters for a pyrolysis system. These parameters can be determined by thermal decomposition behavior studies of the selected solid wastes under pyrolysis.

The objective of the present paper is to present a detailed investigation of thermal decomposition behaviors of jute stick and tamarind seed, in order to develop a simplified rate equation. Pyrolysis kinetics of two selected biomass wastes in Bangladesh have been investigated thermogravimetrically in a nitrogen atmosphere at heating rates of 10 and $60^{\circ} \mathrm{C} / \mathrm{min}$ over a temperature range of 30 to $800^{\circ} \mathrm{C}$. An overall rate equation for the two solid wastes has been modeled satisfactorily by one simplified equation. The kinetic parameters of un-reacted materials based on the Arrhenius form can be determined to be used for rational design and operation of a pyrolysis system.

\section{Experimental}

\subsection{Jute-stick and tamarind seed samples}

Tamarind seed and jute stick were collected locally in Rajshahi, Bangladesh. Two biomass wastes were then dried and crushed into sized and sieved. The proximate and ultimate analysis of the two samples are presented in Table 1. Table 1 shows high volatile content of two selected biomass wastes with good GCVs that represent their potentials for production of bio-fuels by pyrolysis technology.

Table 1. Proximate and ultimate analysis and gross calorific values of the solid wastes

\begin{tabular}{l|ccc|ccccccc}
\hline \multirow{2}{*}{$\begin{array}{l}\text { Biomass } \\
\text { samples }\end{array}$} & \multicolumn{4}{|c|}{ Proximate analysis (wt\%) } & \multicolumn{5}{c}{ Ultimate analysis (wt\%) } & GCV \\
\cline { 2 - 11 } & Moisture & Volatile & Fixed carbon & Ash & C & H & N & O & S & (MJ/kg) \\
\hline Jute-stick & 3.50 & 78.84 & 15.52 & 2.14 & 50.65 & 7.72 & 0.47 & 41.10 & 0.06 & 19.10 \\
\hline Tamarind seed & 7.85 & 67.56 & 20.05 & 4.54 & 47.76 & 9.59 & 0.22 & 42.39 & 0.04 & 18.00 \\
\hline
\end{tabular}

\subsection{Apparatus and experimental conditions}

The Pyris Diamond Thermogravimetric/Differential Thermal Analyzer (TG/DTA) was used to obtain the Thermogravimetric Analysis (TGA) and Differential Thermogravimetric (DTG) data for the prepared samples. The 15-20 mg samples were heated over the temperature range of $30-800{ }^{\circ} \mathrm{C}$ at constant heating rates of 10 and $60{ }^{\circ} \mathrm{C} / \mathrm{min}$ in a high purity nitrogen atmosphere with a flow rate of $100 \mathrm{ml} / \mathrm{min}$.

\subsubsection{Theoretical}

Many research groups (Williams and Besler, 1993; Kim et al., 1995; Islam et al., 2009; Leung and Wang, 1998) assumed that devolatilization in the kinetic analysis of DTG data was a first-order reaction for waste materials. To determine the apparent kinetic parameters, which are useful for engineering purposes, a two-stage first-order reaction (excluding moisture evolution) is assumed in this study. Thus, the following kinetic equation and reaction scheme (Fig. 1) were considered for the thermal degradation process of selected biomass wastes. 


$$
\frac{d X}{d t}=K_{1}\left(1-X_{1}\right)+K_{2}\left(1-X_{2}\right)+\cdots \cdots \cdots
$$

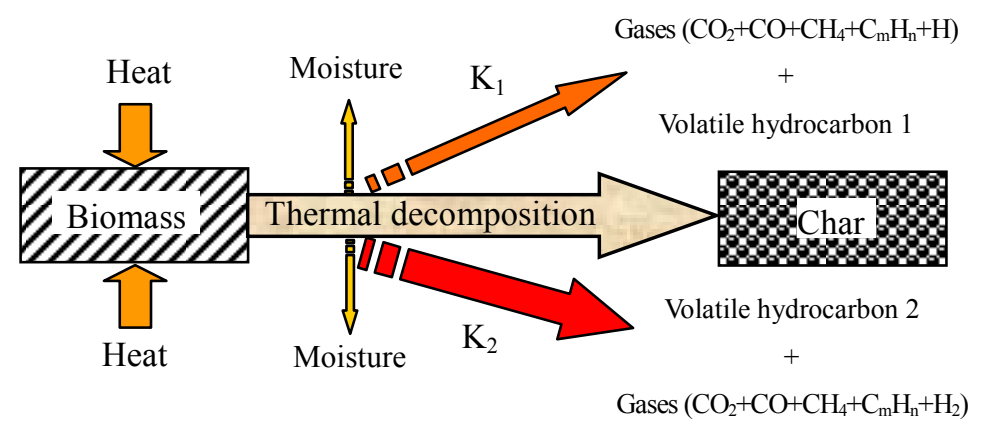

Fig. 1. Thermal decomposition scheme for biomass solid wastes

The Arrhenius Law has also been widely used well for the one-step decomposition reaction and the reaction rate constants $K_{1}, K_{2}$, . . can therefore be obtained from the law:

$$
K_{1}=A_{1} e^{-\frac{E_{1}}{R T}} ; K_{2}=A_{2} e^{-\frac{E_{2}}{R T}} ; \ldots \ldots \ldots
$$

The substitution of the values of the reaction rate constants from Eq. (2) into Eq. (1) yields:

$$
\frac{d X}{d t}=A_{1} e^{-\frac{E_{1}}{R T}}\left(1-X_{1}\right)+A_{2} e^{-\frac{E_{2}}{R T}}\left(1-X_{2}\right)+\cdots \cdots \cdots
$$

Under the condition of a linear heating rate, $\beta=d T / d t$, the Eq. (3) can be written as:

$$
\frac{d X}{d T}=\frac{A_{1}}{\beta} e^{-\frac{E_{1}}{R T}}\left(1-X_{1}\right)+\frac{A_{2}}{\beta} e^{-\frac{E_{2}}{R T}}\left(1-X_{2}\right)+\cdots \cdots \cdots
$$

Where, $X$ is the conversion of the sample, $T$ the absolute temperature, $A$ the frequency factor, $E$ the activation energy, $R$ the universal gas constant $8.314 \mathrm{~J} / \mathrm{mol}-\mathrm{K}, \beta$ the heating rate. Volatile hydrocarbon (1) and Volatile hydrocarbon (2) are produced at lower and higher temperatures, respectively. For two individual reactions in two different temperature regions, the kinetic equation can be written as:

$$
\begin{aligned}
& \frac{d X_{1}}{d T}=\frac{A_{1}}{\beta} e^{-\frac{E_{1}}{R T}}\left(1-X_{1}\right) \\
& \frac{d X_{2}}{d T}=\frac{A_{2}}{\beta} e^{-\frac{E_{2}}{R T}}\left(1-X_{2}\right)
\end{aligned}
$$

The kinetic parameters, including $E_{1}, A_{1}, E_{2}$ and $A_{2}$ can be determined by using the experimental TG and DTG data. In the presented study, these parameters are evaluated by employing the least-square method, which is briefly described below. Taking the logarithm of Eq. (5a) gives:

$$
\ln \frac{d X_{1}}{d T}=\ln \left[\frac{A_{1}}{\beta}\left(1-X_{1}\right)\right]-\frac{E_{1}}{R T}
$$

For fixed values of $\beta$ and $X_{1}$, the first term in the right-hand side of Eq. (6) is constant. Therefore, the equation can be reduced to find a least-square straight line on the $\ln \left(d X_{I} / d T\right)$ versus $1 / T$ plane through the experimental data. It is important to note here that the $d X / d T$ 
data is obtained from the $d X / d t$ data, dividing by the respective heating rate. If Eq. (6) is compared to the simple straight line equation $y=a_{0}+a_{l} x$, it is found that $y=\ln \left(d X_{l} / d T\right), x$ $=1 / T$, the interception $a_{0}=\ln \left[A_{1} / \beta\left(1-X_{1}\right)\right]$, and the slope $a_{1}=-E_{1} / R$. The best values of the regression coefficients (coefficients of the linear least-square fit line), $a_{0}$ and $a_{l}$, that yield the kinetic parameters for low temperature region can be calculated from the equations below:

$$
\begin{aligned}
& m a_{0}+a_{1} \sum_{i=1}^{m} x_{i}=\sum_{i=1}^{m} y_{i} \\
& a_{0} \sum_{i=1}^{m} x_{i}+a_{1} \sum_{i=1}^{m} x_{i}^{2}=\sum_{i=1}^{m} x_{i} y_{i}
\end{aligned}
$$

Using the same method, the values of $X_{2}$ and the corresponding temperature range, Eqs. (5b) yield the kinetic parameters for higher temperature regions. The values of the activation energy and the frequency factor for different values of heating rates and conversion factors can also be determined with the above procedure.

\section{Results and discussion}

Figs. 2-3 show the variations of fractional mass (TG curves) and derivative of mass-loose (DTG curves) with respect to reaction temperature $T$ for two different heating rates, for tamarind seed and jute stick wastes. The comparisons of the TG and DTG curves for the two biomass show that they vary with respective to one another. This is due to the compositional differences between jute stick and tamarind seed. Figs. 2 and 3 show that both the TG and DTG curves shift to higher temperature regions when the heating rates are increased. This means that the reaction zones shift to the higher temperature regions and the peak heights increase with the increase of heating rate. The DTG curves for both of the samples show two-step degradation. Each of the DTG curves has one dominant peak. A second lower-value peak appears at lower temperatures for jute stick and at higher temperatures for tamarind seed. The TG curves have three plateaus each. The first and smaller plateau indicates an initial loss of moisture from the samples continuing up to about $220^{\circ} \mathrm{C}$. Higher temperature drying $\left(>100^{\circ} \mathrm{C}\right)$ occurs due to loss of surface tension bound water of the ground sample. The second plateau occurs about $220-400^{\circ} \mathrm{C}$, which largely reflects the thermal decomposition of cellulose and hemicelluloses. The third plateau starts

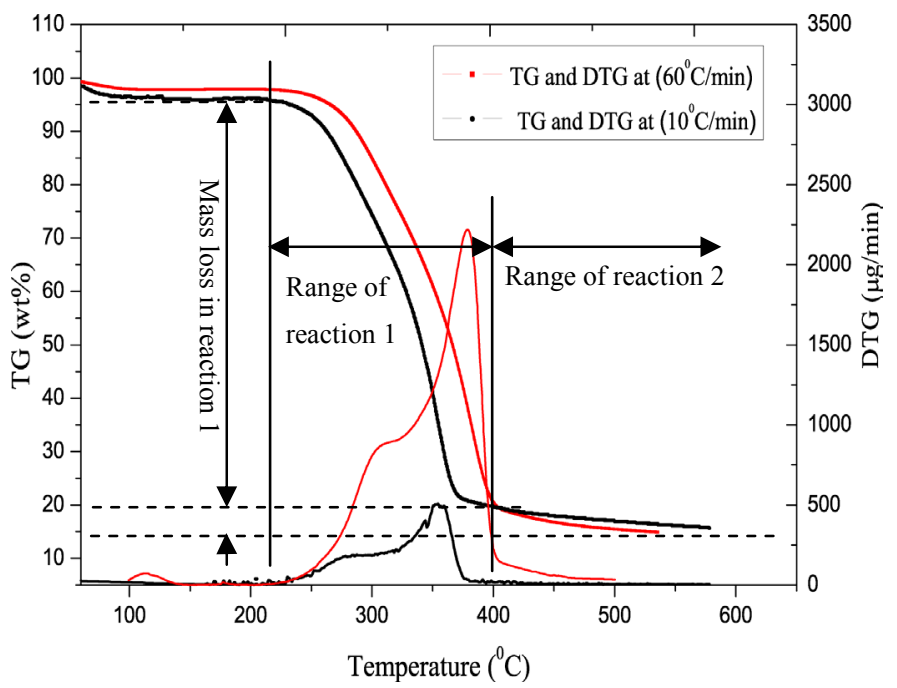

Fig. 2. TG and DTG plots for jute stick at heating rates of 10 and $60^{\circ} \mathrm{C} / \mathrm{min}$ 
around $>400^{\circ} \mathrm{C}$, which largely reflects the thermal decomposition of lignin (Williams and Besler 1993, Raveendran et al., 1991 and Min et al., 2007, Yang et al., 2006 and 2007). The nature of a TG curve with corresponding DTG peaks gives a clear indication of the number of stages of the thermal degradation. The total weight loss is $75.5-77.2 \mathrm{wt} \%$ for tamarind seed, 84.4-85.5 wt $\%$ for jute stick. The total weight loss for tamarind seed is comparatively lower than that of jute stick. The conversions of the two biomass samples were completed within the temperature around $500{ }^{\circ} \mathrm{C}$. For both of the samples, about $3-8 \%$ of total weight loss is due to the moisture evolution (dehydration). The amount of weight lost in reaction 1 , are $73-75 \%$ for jute stick and $52-56 \%$ for tamarind sheed. While the amount of weight lost in reaction 2 for jute stick and tamarind seed are $6.4-7.5 \%$ and $11.5-12.2 \%$, respectively.

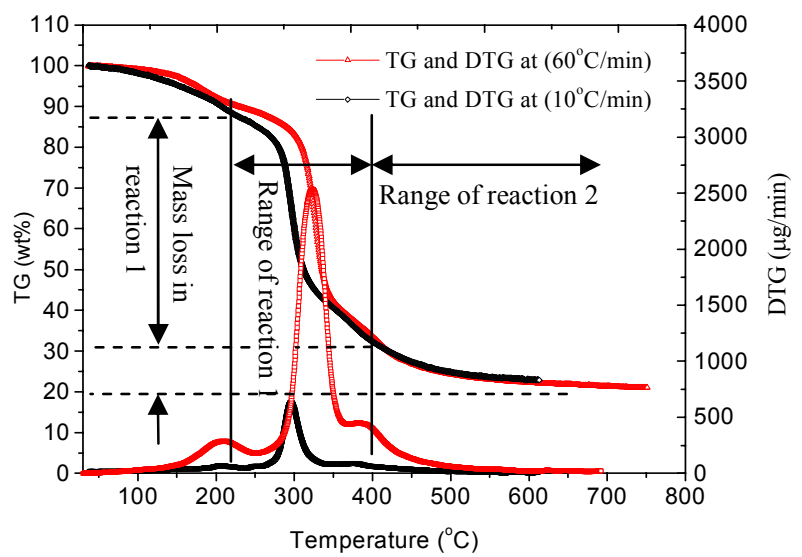

Fig. 3. TG and DTG plots for tamarind seed at heating rates of 10 and $60^{\circ} \mathrm{C} / \mathrm{min}$

Table 2. Comparisons of kinetic parameters of the two selected biomass

\begin{tabular}{|c|c|c|c|c|c|c|c|}
\hline \multirow{2}{*}{$\begin{array}{l}\text { Biomass } \\
\text { samples }\end{array}$} & \multirow{2}{*}{$\begin{array}{c}\text { Heating } \\
\text { rate, } \beta \\
\left({ }^{\circ} \mathrm{C} / \mathrm{min}\right)\end{array}$} & \multicolumn{3}{|c|}{ Low temperature region } & \multicolumn{3}{|c|}{ High temperature region } \\
\hline & & $\begin{array}{c}\text { Temp. range } \\
\left({ }^{\circ} \mathrm{C}\right)\end{array}$ & $\begin{array}{c}E \\
(\mathrm{~kJ} / \mathrm{mol})\end{array}$ & $\begin{array}{c}\mathrm{A} \\
\left(\min ^{-1}\right)\end{array}$ & $\begin{array}{c}\text { Temp. range } \\
\left({ }^{\circ} \mathrm{C}\right)\end{array}$ & $\begin{array}{c}E \\
(\mathrm{~kJ} / \mathrm{mol})\end{array}$ & $\begin{array}{c}\text { A } \\
\left(\min ^{-1}\right)\end{array}$ \\
\hline \multirow{2}{*}{$\begin{array}{l}\text { Tamarind } \\
\text { seed }\end{array}$} & 10 & $220 \sim 400$ & 16.02 & $4.1 \times 10^{3}$ & $300 \sim 500$ & 53.37 & $6.8 \times 10^{4}$ \\
\hline & 60 & $220 \sim 410$ & 16.33 & $0.42 \times 10^{3}$ & $290 \sim 550$ & 61.96 & $3.6 \times 10^{5}$ \\
\hline \multirow{2}{*}{ Jute stick } & 10 & $220 \sim 380$ & 42.88 & $3.2 \times 10^{5}$ & $300 \sim 500$ & 104.1 & $9.8 \times 10^{5}$ \\
\hline & 60 & $220 \sim 400$ & 44.19 & $2.4 \times 10^{4}$ & $327 \sim 555$ & 83.22 & $7 \times 10^{5}$ \\
\hline
\end{tabular}

The kinetic parameters of the tow biomass pyrolysis obtained from the proposed model, Eqs. (5a)-(5b), are presented in Table 2. The tabulated results show that the values of the activation energy and the frequency factor for the two samples in this study are lower than those obtained by Min et al. (2007), Caballero et al. (1997) and Cao et al. (2004) but higher than those obtained by Peng et al. (2001) in both the lower and higher temperature regions. This may be due to the fact that the kinetic parameters determined by the studies were for biomass solid waste of different compositions.

The apparent kinetic parameters are obtained from the average of the computed kinetic parameters values for the two different heating rates and for the two reaction stages. The value of the apparent activation energy is $E=36.92 \mathrm{~kJ} / \mathrm{mol}$ and the frequency factor is $A=$ $1.08 \times 10^{5} \mathrm{~min}^{-1}$ for tamarind seed and $E=68.59 \mathrm{~kJ} / \mathrm{mol}$ and $A=5.6 \times 10^{5} \mathrm{~min}^{-1}$ for jute stick. Using the values of the apparent kinetic parameters, a simplified rate equation for two types of biomass can be modeled throughout the pyrolysis reaction in nitrogen atmosphere as follows: 


$$
\frac{d X}{d T}=\frac{3.34 \times 10^{5}}{\beta} e^{-\frac{5275.50}{T}}(1-X) \quad \text { OR } \quad \operatorname{In} K=\operatorname{In}\left(\frac{3.34 \times 10^{5}}{\beta}\right)-\frac{5275.50}{T}
$$

The above equation can be integrated using the fourth order Runge-Kutta numerical integration scheme to obtain the theoretical conversion factor versus temperature for the different heating rates. Fig. 4 shows the TG data for the two types of biomass and the computed values for the heating rates of 10 and $60^{\circ} \mathrm{C} / \mathrm{min}$. It can be seen that the computed values for the heating rates of 10 and $60^{\circ} \mathrm{C} / \mathrm{min}$ agree fairly well with the two sets of TG data for the corresponding heating rates.

The Arrhenious plots of $\ln K$ versus $1000 / T$ together with the DTG data for the tamarind seed and jute stick are shown in Figs. 5 and 6 for heating rates of 10 and $60^{\circ} \mathrm{C} / \mathrm{min}$, respectively. It can be seen that the derived equation based on the two reactions in the two different temperature regions fit well with the two sets of data for the heating rates of 10 and $60^{\circ} \mathrm{C} / \mathrm{min}$.

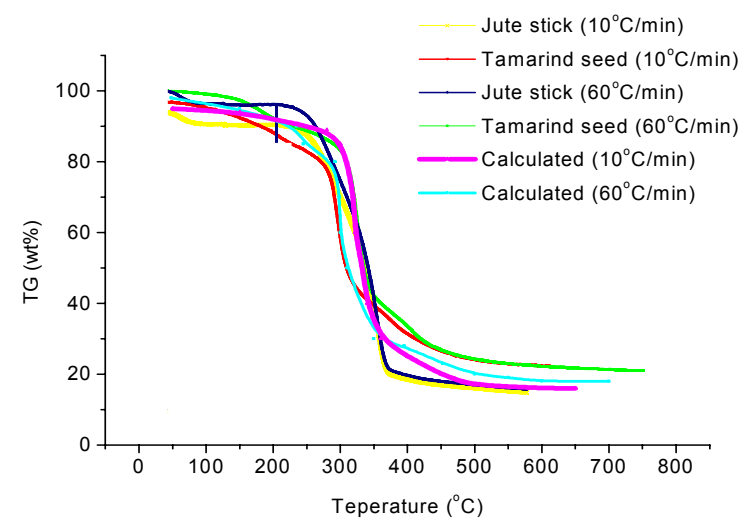

Fig. 4. Comparison of TG data and computed values from numerical integration of rate equation.

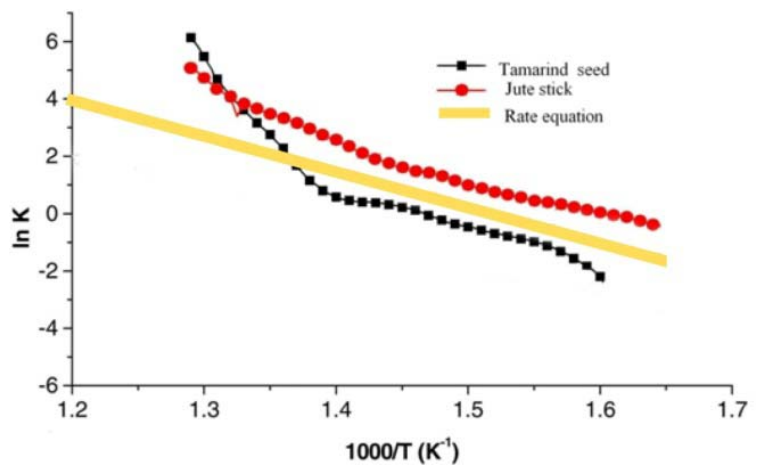

Fig. 5. Arrhenius plots of tamarind seed and jute stick in nitrogen at heating rate of $10^{\circ} \mathrm{C} / \mathrm{min}$. 


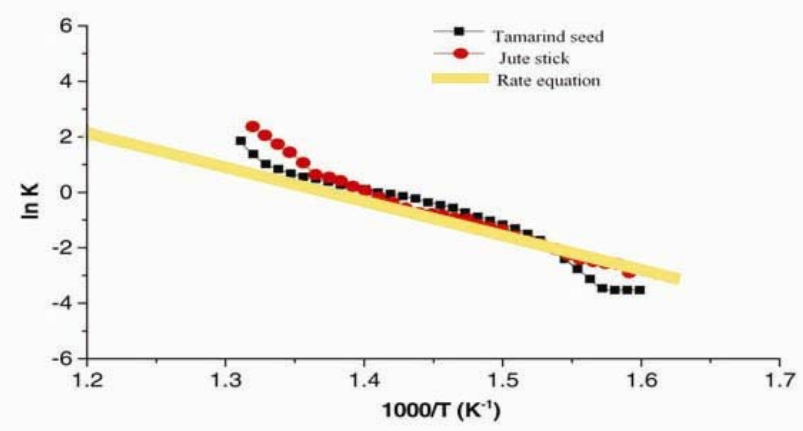

Fig. 6. Arrhenius plots of tamarind seed and jute stick in nitrogen at heating rate of $60^{\circ} \mathrm{C} / \mathrm{min}$.

\section{Conclusions}

Under the thermal decomposition behavior study it may be concluded that the weight loss region is shifted to a higher temperature range and the weight loss rate is increased with increasing heating rate. The activation energy increase while frequency factor decrease with increasing heating rate. The percentage of total weight loss is higher for jute stick and is lower for tamarind seed. The rate equation for the two types of biomass wastes can be modeled satisfactorily by a simplified equation, which is found to fit the experimental data fairly well. The results of this paper may be useful for rational design and operation of a pyrolysis system for potentially thermal conversion of biomass solid wastes into bio-fuels.

\section{Acknowledgements}

The work is supported by 'Grant-In-Aid for Scientific Research' of the Japan Society for the Promotion of Science (ID No.: P 09094).

\section{References}

Bridgwater, A.V., Toft, A.J. and Brammer, J.G. (2002). A techno-economic comparison of power production by biomass fast pyrolysis with gasification and combustion. Renewable and Sustainable Energy Reviews, 6: pp. 181-248.

Garcia-Perez, M., Chaala, A. and Roy, C. (2002). Vacuum pyrolysis of sugarcane bagasse J. Anal. Appl. Pyrolysis, 65: pp. 111-136.

Leung D.Y.C., Wang C.L. (1998). Kinetic study of scrap tire pyrolysis and combustion. J. Anal. Appl. Pyrolysis, 45:153-169.

Min F., Zhang M. and Chen Q. (2007). Non-isothermal kinetics of pyrolysis of three kinds of fresh biomass. J China University of Mining \& Technology 17(1):105-111

Peng, W., Wu, Q., Tu, P., Zhao, N. (2001). Pyrolytic charateristics of microalgae as renewable energy source determined by thermogravimetric analysis. Bioresource Technology, 80: pp. 1-7.

Cao, Q., Xie, K., Bao, W., Shen, S. (2004). Pyrolytic behavior of waste corn cob. Bioresource Technology, 94: pp. 83-89.

Kim S.D., Park J.K., Chun H.D. (1995). Pyrolysis kinetics of scrap tyre rubbers. I: Using DTG and TGA. J. Environ. Eng. 121:507-514.

Carballero JA, Conesa JA, Font R. and Marcilla A. (1997). Pyrolysis kinetics of almond shells and olive stones considering their organic fractions. J. Anal. Appl. Pyrolysis, 42:159-175.

Williams P.T. and Besler S. (1993). The pyrolysis of rice husks in a thermogravimetric 
analyzer and static batch reactor. Fuel, 72(2): pp. 151-158.

Islam, MR., Haniu, H. and Fardoushi, J. (2009). Pyrolysis kinetics behavior of solid tire wastes available in Bangladesh. Waste Management, 29( 2): pp. 668-677.

Raveendran K., Ganesh A. and Hhilar K.C. (1991). Pyrolysis charateristics of biomass and biomass components. Fuel 70(7):803-809

Yang, H., Yan, R., Chen, H., Zheng, C., Lee, D. H., Liang, D.T. (2006). In-dept investigation of biomass pyrolysis based on three major components: Hemicellulose, Cellulose and Lignin. Energy \& Fuels, 20: pp. 388-393.

Yang, H., Yan, R., Chen, H., Lee, D. H., Zheng, C. (2007). Charateristics of Hemicellulose, Cellulose and Lignin pyrolysis. Fuels, 86: pp. 1781-1788. 